\title{
KEMIČNO OROŽJE - POSEBNOST PRVE SVETOVNE VOJNE ALI ŠE DANES PRETEČA NEVARNOST
}

\author{
CHEMICAL WEAPONS - PARTICULARITY \\ OF WORLD WAR I OR \\ A STILL IMMINENT DANGER
}

Povzetek Kemično orožje je svoj največji razmah doživelo med prvo svetovno vojno, ko so ga uporabljale sile obeh v vojno vpletenih strani, čeprav je bila s haaškimi deklaracijami uporaba strupov v bojne namene prepovedana že pred vojno. Med prvo svetovno vojno je bilo razvitih in uporabljenih več vrst kemičnega orožja, pri čemer so največjo uporabnost ter uničevalno moč pokazali klor, fosgen in iperit. Odziv na uporabo smrtonosnega tihega orožja je bil razvoj zaščitnih mask, pri čemer pa mnoge niso zadoščale standardom in so se $\mathrm{v}$ kriznih trenutkih pokazale kot neučinkovite. Uporaba kemičnega orožja je v prvi svetovni vojni povzročila veliko žrtev, vendar ni odločilno vplivala na končni izid vojne. Zaradi izjemne smrtonosnosti in uničujočih fizioloških ter psiholoških posledic, ki jih je povzročilo kemično orožje v času tako imenovane Velike vojne, so si mednarodne sile po letu 1918 prizadevale zagotoviti, da se ta tihi ubijalec ne bi več uporabljal v bojne namene. To je bil tudi eden izmed vzrokov, zakaj ni prišlo do večjega razmaha uporabe kemičnega orožja po tem letu. Prizadevanja mednarodne skupnosti po izkoreninjenju bojnih strupov pa niso preprečila razvoja znanosti, ki je v 20. stoletju prinesel odkritja novih strupenih orožij, ki jih v prvi svetovni vojni še niso poznali.

Ključne Kemično vojskovanje, orožje za množično uničevanje, zaščita pred kemičnim besede vojskovanjem, prva svetovna vojna, kemični terorizem.

Abstract Chemical weapons saw their largest growth during World War I, when it was used by the forces of both involved parties despite the fact that the use of casualty agents had been banned by Hague declarations even before the war. Several types of chemical weapons were used and developed during World War I with chloride, phosgene and mustard gas proving to be most useful and destructive. As a response to the use of this lethal silent weapon protection masks were developed. However, many of them did not meet the standards and proved to be ineffective during crisis. 
The use of chemical weapons in World War I caused numerous casualties, but did not decisively impact the final outcome of the war. Due to the extremely lethal nature and devastating physiological and psychological consequences caused by chemical weapons during the Great War, international forces after 1918 made every effort to never use this silent murderer in combat again. This was also one of the reasons why chemical weapons did not see too large of a development after this period. However, international efforts to root out casualty agents did not prevent the scientific development, which in the $20^{\text {th }}$ century brought the discovery of new toxic weapons which had not been known during World War I.

\section{Key words Chemical warfare, weapons of mass destruction, protection against chemical} warfare, World War I, chemical terrorism.

Uvod Leta 1914 je Evropo zajela težko pričakovana vojna. Želja po vojni v Evropi je bila velika, saj človeštvo do tedaj še ni izkusilo spopada svetovnega obsega. Obe sprti strani, centralne sile in antanta, sta verjeli v svoje vojaške zmožnosti in bili prepričani, da bosta v vojni zmagali. Kmalu pa se je izkazalo, da vojna ne bo izpolnila pričakovanj vpletenih. Namesto da bi se končala v nekaj mesecih, se je morija zavlekla v nekaj let. Postala je vojna izčrpavanja. Vojna je potekala na stabiliziranih frontah strateškega obsega, ki brez močne industrije v zaledju ne bi obstale. V ospredje je prišlo preizkušanje industrijske moči vpletenih strani. Pomembno vlogo v vojni agoniji je imelo artilerijsko orožje, ki je med drugim tudi precej prispevalo k temu, da se je vojna spremenila v pozicijsko. Nobeno izmed konvencionalnih orožij ni bilo sposobno prebiti fronte in doseči večjega premika, zato so bile vojaške oblasti dovzetne za kakršne koli bojne izume, ki bi prinesli spremembo. Napredek kemične znanosti v 19. in začetku 20. stoletja sta s pridom izkoristili obe vojskujoči se strani.

\section{METODE}

Vodilo prispevka je predstaviti obseg uporabe kemičnega orožja v prvi svetovni vojni in uporabo po koncu Velike vojne. V drugem delu nas je zanimalo, koliko kemično orožje še danes pomeni grožnjo za človeštvo. V pomoč so nam bili predvsem nemški, francoski, britanski in ameriški viri, saj je kemična vojna potekala predvsem na zahodni fronti. Tako so viri in literatura, ki se ukvarja s kemičnimi agensi v prvi svetovni vojni na zahodni fronti, precej obsežni. Obravnav uporabe kemičnih agensov na drugih frontah je manj, kljub temu pa vendarle najdemo informacije o kemičnih napadih na primer na slovenskih tleh. V zvezi s tem nas je zanimalo tudi, kako obsežne so bile posledice uporabe teh strupenih snovi za prihodnje generacije.

$\mathrm{Z}$ metodo primerjalne analize smo raziskali, koliko je bila izkušnja prve svetovne vojne na področju kemičnih napadov poučna za človeštvo. Tako smo se posvetili uporabi kemičnih agensov po prvi svetovni vojni in primerjali množičnost uporabe. 
V ožjem pogledu nas je zanimalo, ali ukrepi mednarodne skupnosti za kemično razoroževanje res pomenijo varnost pred morebitnim neslišnim in nevidnim sovražnikom. Analiza se posveča vzrokom, zaradi katerih so bile prepovedi uporabe kemičnih agensov upoštevane oziroma niso bile upoštevane $\mathrm{v}$ različnih časovnih obdobjih.

\section{RAZVOJ KEMIČNEGA OROŽJA}

Razvoj kemije kot znanosti se je začel šele v 19. stoletju in proizvodnja kemikalij je kmalu pokazala, da je veliko teh snovi v določenih količinah za človekovo zdravje in življenje nevarnih (Broyles, 2005). V napredku kemične znanosti in industrije je prednjačila Nemčija. Po mnenju Andréja Moureuja brez svoje industrije in še posebej brez kemične industrije ne bi napovedala vojne Franciji leta 1914. André Moureu je leta 1920 izdal delo Kemija in vojna (fr. La Chimie et la Guerre), v katerem je analiziral razvoj kemične industrije v Nemčiji pred Veliko vojno in ugotavljal veliko zaostajanje Francije za nemškim napredkom leta 1914 (po Lejaille, 2013, Introduction).

Generalštabi vpletenih držav leta 1914 niso predvidevali dolgotrajne vojne in nanjo tudi niso bili pripravljeni. Ko se je vojna spremenila v pozicijsko in bojevanje $\mathrm{v}$ agonijo, so vsi upali na izum »čudežnega orožja«, ki bi s svojo izjemno uničevalno močjo omogočilo hiter preboj fronte in zmago na bojišču (Lejaille, 2013, Introduction). 14. septembra 1914 je vodenje nemškega generalštaba iz rok ostarelega generala von Moltkeja prevzel general von Falkenhayn, ki je takoj ukazal začetek raziskav za iznajdbo učinkovitega kemičnega orožja (Legg in Parker, 2002).

Vojna je že jeseni 1914 postala pozicijska in med položaji sovražnikov je bilo pogosto le nekaj sto metrov razdalje, zato je imela artilerija težave, saj je pogosto povzročila precej škode tudi lastni pehoti. Poleg tega je artilerija s težavo dosegala rove $\mathrm{v}$ skritih predelih, saj so postajali nasprotnikovi rovi vse bolje utrjeni in vse globlje skopani. Te težave artilerije bi lahko premostilo novo skrivnostno orožje, ki bi se nevidno in tiho širilo v nasprotnikove položaje in onesposobilo moštvo. O tem orožju so razmišljali na obeh straneh, v raziskavah pa so prednjačili Nemci pod vodstvom Fritza Haberja (Legg in Parker, 2002). ${ }^{1}$

\footnotetext{
Fritz Haber je bil znamenit kemik in pozneje Nobelov nagrajenec, ki je vodil nemški raziskovalni program kemičnega vojskovanja. Poimenovali so ga »oče kemične vojne«, Nobelovo nagrado za kemijo je dobil leta 1918 za sintezo amoniaka (Fitzgerald, 2008). Z njim je kemijska znanost postala ne samo nosilka napredka človeštva, temveč tudi uničujoča sila ekstremnih razsežnosti. Njegov moto je bil, da mora znanost v miru služiti človeštvu, v vojni pa domovini (nem. Im Frieden für die Menschheit, im Krieg für das Vaterland). Čeprav je Haber služil domovini, mu je ta pozneje obrnila hrbet in je moral leta 1933 bežati v Anglijo, saj je bil judovskega porekla. Veliko njegovih sorodnikov je končalo svojo življenjsko pot v nemških koncentracijskih taboriščih. Nekateri izmed njih so bili žrtve njegovega lastnega izuma-ciklona B (Hofmann, 2014).
} 


\section{PRVA UPORABA KEMIČNEGA OROŽJA V PRVI SVETOVNI VOJNI}

Čeprav prevladuje mnenje, da so prvi uporabili kemično orožje Nemci na zahodni fronti, pa je dejstvo, da so to orožje leta 1914 prvi uporabili Francozi. Francozi so želeli z uporabo kemičnega orožja doseči, da bi sovražnikove enote pregnali s položajev, ki jih artilerija ni dosegla (Lejaille, 2013, Introduction). Že avgusta 1914 so francoske sile na zahodni fronti uporabljale 26-milimetrske granate, imenovane cartouches suffocantes, polnjene s solzivcem etil bromoacetatom. ${ }^{2} \mathrm{Na}$ bojišču je bil njegov učinek tako zanemarljiv, da nemške sile uporabe kemičnega agensa niso niti zaznale (Hutchinson, 2004, str. 200). Prvi poskusi uporabe kemičnega orožja niso bili obetavni.

Odgovor nasprotnih sil pa je vendarle prišel v samo nekaj mesecih. 27. oktobra 1914 so Nemci izstrelili 3000 artilerijskih izstrelkov s kodnim imenom Ni-Schrapnell, polnjenih z dražljivcem dianisdin klorosulfonatom, na britanske enote $\mathrm{v}$ bližini Neuve-Chapelle, vendar je bil kemični napad brez učinka. Najverjetneje je bilo kemično sredstvo uničeno že z eksplozijo ob stiku z bojiščem. Koncentracija strupenega agensa je bila premajhna, da bi povzročila škodo sovražniku (Wietzker, 2006, str. 30). Na vzhodni fronti pa so nemške sile kemično orožje prvič uporabile 30. januarja 1915 v obliki mešanice ksililbromida, ksililenbromida (s kodnim imenom T-Stoff) in benzilbromida pri Bolimówu na območju današnje Poljske, vendar so nizke temperature preprečile širjenje strupa, zaradi česar ni imel posebnega učinka (Hutchinson, 2004, str. 199).

\section{KLOR IN ZAČETEK KEMIČNE VOJNE}

Leta 1915 so nemški znanstveniki pod vodstvom Fritza Haberja v Inštitutu cesarja Viljema v Berlinu (nem. Kaiser Wilhelm Institut) razvili klor za bojno uporabo. ${ }^{3}$ Klor so vstavili v posebej za to izdelane jeklenke, da bi ga iz njih izpustili na bojišče $\mathrm{v}$ rove nasprotnikovih vojakov. Nemško vrhovno poveljstvo je od tega orožja pričakovalo, da bo pregnalo vojake iz strelskih jarkov, ne pa množičnega smrtonosnega učinka (Fitzgerald, 2008). Klor je težji od zraka, kar je zagotavljalo, da se bo dlje časa zadrževal na bojnih položajih (Cobb, 2000, str. 43). Aprila 1915 so bili Nemci pripravljeni na prvi večji napad s klorom. Francoske sile so prejele obvestila belgijske vojske in poročila nemških zajetih vojakov, da se pripravlja nemški napad s kemičnim orožjem, vendar jih niso jemale resno. Do tedaj se raba kemičnega orožja na bojišču ni izkazala kot učinkovita in ni povzročila resnih posledic. Druga bitka pri Ypresu v Belgiji pa je prinesla veliko presenečenje (Duffy, 2009) in dokazala, da so bojni strupi orožje za množično uničevanje (Brezina, 2005, str. 23). 22. aprila 1915 je nemška vojska ob primernem vetru nad strelske jarke antantnih sil izpustila 180 ton klora iz 5730 jeklenk (A short History of CW

Ta solzivec je francoska policija uporabljala za začasno onesposobitev in ni imel smrtonosnega učinka. Ne glede na to so strokovnjaki menili, da ga je vredno preizkusiti tudi na fronti (Hutchinson, 2004, str. 200).

3 Klor je močan dražljivec - dušljivec, ki poškoduje oči in dihalne poti ter organe. Ob večji koncentraciji in daljšsem času vdihavanja tega agensa pride do smrti. Dušljivce so Nemci poimenovali tudi zeleni križ (Grünkreuz), saj so izstrelke s tem strupom označevali z zelenim križem. 
during WWI., online) (po drugih virih pa 150 ton, gl. npr. Lejaille, 2013; oziroma 168 ton). Na francosko stran je veter zanesel 6 kilometrov dolg in od 600 do 900 metrov globok plinski oblak. Alžirski vojaki, ki so se bojevali na strani Francije, so bili prve žrtve. V paniki so bežali iz rovov pred smrtonosnim oblakom, ki se je tiho širil po njihovih položajih (Wietzker, 2006, str. 45). Klor se je zaradi svoje teže nakopičil v strelskih jarkih, francoske sile pa so bile zaradi številnih žrtev prisiljene v umik, kar so Nemci izkoristili in zavzeli francoske položaje (Brezina, 2005, str. 23).

Presenečeni antantni branitelji so v drugi bitki pri Ypresu v enem samem dnevu izgubili 18.000 mož, 2000 pa so jih zajele nemške sile. Rumeno-zeleni oblak bojnega plina je uničil vse, česar se je dotaknil. Nad izjemno uničevalno močjo novega orožja niso bili presenečeni samo branitelji, pač pa tudi napadalci. Nemci so si sicer želeli, $\mathrm{v}$ resnici pa niso pričakovali takega uspeha, zato niso imeli pripravljenih dovolj sil, da bi prebili fronto in v celoti izkoristili sovražnikovo presenečenje (Duffy, 2009). Napredovali so 4,5 milje v nasprotnikove položaje, dokler jih ni ustavila hitro improvizirana obramba antantnih sil. Imeli so le primitivno zaščito pred strupenim orožjem, kar je še dodatno oteževalo njihov prodor (Heller, 1984, str. 10). Nemci so v naslednjih dneh napad s klorom še nekajkrat ponovili. Napadli so 24. aprila 1915 kanadske položaje in 2. ter 5. maja britanske, vendar z manj uspeha, saj je bila količina uporabljenega agensa bistveno manjša kot usodnega dne (Hutchinson, 2004, str. 199). Število žrtev plinskega napada še danes ni popolnoma jasno. Antantne sile so imele v enem dnevu vsaj 2500 mrtvih oziroma 4200 pogrešanih (Lejaille, 2013, Vagues allemandes), po nekaterih drugih virih pa so imele približno $5000 \mathrm{mrtvih}$ in od 10.000 do 15.000 ranjenih (Wottke, 2014).

Antantne sile so obsojale nemško uporabo bojnih strupov ${ }^{4}$, po drugi strani pa so tudi same pospešile razvoj kemičnega orožja, da bi ga lahko čim bolj učinkovito uporabile na bojišču (Brezina, 2005, str. 23). Tako pomeni »črni dan Ypresa« trenutek, ko je »duh ušel iz steklenice«, saj so po tem napadu uporabljali kemično orožje v večji meri na obeh straneh. Ta dan je dokazal, da je kemično orožje res učinkovito bojno sredstvo in ima potencial orožja za množično uničevanje. Nemška stran je do konca vojne izvedla še približno 50 plinskih napadov s klorom, pri čemer pa je imela zaradi nenadnih sprememb vetra žrtve tudi v svojih vrstah. Klor so uporabili tako na zahodni kakor tudi na vzhodni fronti. 6. avgusta 1915 so uporabili klor proti ruskim enotam, ki so branile trdnjavo Osowiec, vendar je branilcem kljub plinskemu napadu uspelo obdržati trdnjavo v svojih rokah. Največji napad s klorom so nemške sile izvedle v noči z 19. na 20. januar 1916 pri Reimsu, kjer so izpustili v ozračje 550 ton klora iz 25.000 jeklenk (Duffy, 2009).

\footnotetext{
Svoj protest proti uporabi novega orožja je izrazila tudi žena izumitelja Fritza Haberja Clara Immerwahr, prva promovirana kemičarka v Nemčiji. Po uspešni uporabi klora pri Ypresu si je demonstrativno zadala smrtni udarec in se ustrelila v prsi. Po njenem mnenju bi morala znanost služiti miroljubnemu razvoju človeštva in ne njegovemu uničenju (Brezina, 2005, str. 23).
} 
Po nemškem uspehu pri Ypresu so si tudi Britanci prizadevali uporabiti klor kot orožje. Prvič jim je to uspelo 25. septembra 1915 pri kraju Loos, kjer so izvedli napad s 150 tonami klora. V tem napadu so prvič uporabili možnar, s katerim so izstreljevali projektile s smrtonosnimi kemičnimi agensi, imenovanimi s kodnim imenom rdeča zvezda (angl. Red Star). Nemci so bili na napad slabo pripravljeni. Strupeni plin je preprečil nemškim častnikom in podčastnikom, da bi iz zaščitnih mask dovolj glasno poveljevali, zaradi česar njihovi podrejeni niso slišali njihovih ukazov (Heller, 1984, str. 11). Sicer pa je bil kemični napad polom, saj se je zaradi šibkega vetra plin zadržal na območju nikogaršnje zemlje, deloma pa ga je zaneslo celo Britancem v lastne vrste. Zaradi te grozljive izkušnje so Britanci pospešili raziskave na področju zaščite in izdelali flanelasto plinsko masko. 9. in 19. januarja so uporabili v napadu pri Fromellesu mešanico iz 80 odstotkov klora in 20 odstotkov žveplovega klorida (A short History of CW during WWI., online). Francozi so prve obrate za proizvodnjo klora odprli leta 1915 z britansko pomočjo. Prvi plinski napad s klorom pa so izvedli šele 15. februarja 1916 pri Reimsu. V primerjavi z Britanci niso izpuščali plina iz jeklenk, temveč so kot glavno orožje uporabljali granate s kemičnimi agensi (A short History of CW during WWI., online). Zaradi žrtev v lastnih vrstah so si na obeh straneh prizadevali razviti izstrelke, s katerimi bi izstrelili kemične agense na nasprotnikove položaje in ne bi ogrožali svojega moštva (Duffy, 2009).

\section{FOSGEN - TIHI UBIJALEC}

Fosgen je leta 1812 odkril angleški kemik John Davy, ki ga je uporabljal kot kemično barvilo za blago. ${ }^{5} \mathrm{~V}$ bojne namene so ga prvi preizkusili Francozi pod vodstvom kemika Victorja Grignarda. Z njim so želeli preseči pomanjkljivosti klora na bojišču. Klor se na prostem zadržuje kot zeleno-rumen oblak in ga je zelo lahko opaziti, fosgen pa je brezbarven, kar je oteževalo njegovo detekcijo (Lejaille, Introduction). Fosgen je prvič uporabila nemška vojska 31. maja 1915 pri Ypresu na zahodni fronti. Uporabili so mešanico iz 95 odstotkov klora in 5 odstotkov fosgena. Pozneje so nemške enote uporabljale v napadih čisti fosgen (Wottke, 2014). Francozi so fosgen prvič uporabili 21. februarja 1916 pri Verdunu in za njimi so ga za bojevanje uporabljale vse v vojno vpletene države (Ochsenbein, 2007). Maja 1915 so Nemci uporabili fosgen tudi proti ruskim silam pri Bolimówu na Bzuri. Uporabili so 240 ton klora, ki mu je bilo dodanega še 5 odstotkov fosgena. Napad z mešanico klora in fosgena je povzročil več tisoč smrtnih žrtev. Velik napad z mešanico klora in fosgena so izvedli Nemci 19. decembra 1915 pri Wieltjeju v Flandriji, kjer so proti Britancem izpustili 180 ton strupenega plina iz 4000 jeklenk (Brezina, 2005, str. 25). 1. septembra 1917 so na vzhodni fronti na reki Dvini pred Rigo uporabili kombinacijo obeh agensov in pobili tisoče ruskih vojakov, ki so bili zaščiteni le s

\footnotetext{
Fosgen se uvršča v skupino dušljivcev in povzroči hude poškodbe pljuč, pljučni edem, pogosto tudi smrt. V človeško telo prodira izključno skozi dihalne organe. Je brezbarven in negorljiv plin z značilnim vonjem po sveže pokošenem senu. Uporablja se za sintezo pesticidov, barvil, umetnih smol in plastičnih mas (Ušeničnik, 1999, str. 290-291). V prvi svetovni vojni je fosgen povzročal visoko smrtnost zaradi pljučnice, za katero $v$ tistem času še ni bilo antibiotikov (Crone, 1992, str. 18). Posebna lastnost fosgena je, da se učinki navadno pokažejo šele nekaj ur po izpostavitvi. Simptomi so hudo kašljanje in davljenje žrtve (Cobb, 2000).
} 
slabim in neučinkovitim respiratorjem (Heller, 1984, str. 25). Na bojišču so Nemci uporabljali tudi difosgen, s kemijskim imenom triklorometil kloroformat. Fosgenu so dodali kloroform, ki je prehajal skozi tedanje zaščitne maske, in tako pridobili še bolj strupen agens (Jane's, str. 297). Mešanico klora in fosgena so uporabljale tudi antantne sile. Britanci so od junija do novembra 1916 izvedli 110 plinskih napadov z mešanico klora in fosgena na zahodni fronti. Nemci so leta 1917 fosgen spuščali tudi iz letal (Fitzgerald, 2008). V prvi svetovni vojni je fosgen povzročil okoli 80 odstotkov smrti, povzročenih z bojnimi plini (Cobb, 2000).

\section{GORČIČNI PLIN - IPERIT - KRAL BOJNIH STRUPOV}

Iperit je v 19. stoletju odkril angleški kemik Samuel Guthrie, ki je zmešal klor z Žveplom. ${ }^{6}$ Prvič so na bojišču iperit uporabili Nemci ponoči z 12. na 13. julij 1917 pri Ypresu v Belgiji. Tekočino bojnega strupa so uskladiščili v artilerijske granate, ki so jih izstrelili proti sovražniku, in ob eksploziji se je tekočina pretvorila v plinasto stanje. ${ }^{7}$ Antantni zavezniki so po francoskem prizadevanju že v enem letu začeli izdelovati svoj iperit, kar je med drugim pomembno pripomoglo k nemškemu spoznanju, da leta 1919 ne bodo zmogli vojaško parirati močnejši antantni produkciji nevarnega kemičnega sredstva. Poleg tega je bilo na strani zaveznikov tudi dejstvo, da je na zahodni fronti veter v večji meri pihal z zahoda na vzhod, kar je Nemce še dodatno oviralo pri vodenju kemične vojne (Jones, 2014a).

Do konca vojne je iperit zahteval največ smrtnih žrtev med vsemi uporabljenimi kemičnimi orožji tedanjega časa (Cobb, 2000). Nemci so ga uspešno uporabljali na bojišču predvsem v hladnejših mesecih, poleti pa se je izkazal za manj uspešnega (Jones, 2014a). Leta 1918 je kemična vojna dosegla vrhunec. Povprečno vsaka tretja granata je bila polnjena s kemičnim agensom. V spomladanskih ofenzivah leta 1918 so se Nemci še posebej zatekali k uporabi kemičnega orožja. Z njim so blokirali nasprotnikovo logistično oskrbo, onemogočili delovanje artilerije, nevtralizirali močnejše točke nasprotnika in njihove enote so vse pogosteje zahtevale, da bojni strupi spremljajo streljanje pehote in artilerije (Heller, 1984, str. 25). Slikovit primer

\footnotetext{
Zaradi vonja, ki je spominjal na gorčico, so novo sredstvo imenovali tudi gorčični plin in spada v skupino mehurjevcev (angl. mustard gas, nem. Senfgas). Pravzaprav iperit ni plin, temveč slabo hlapljiva tekočina, vendar se je uveljavil tudi za to sredstvo izraz plin (Crone, 1992, str. 18). Francozi so ga poimenovali iperit (fr. Yperite) po mestu, v katerem je bil prvič uporabljen, Nemci pa rumeni križ (nem. Gelbkreuz) po znaku, s katerim so označevali izstrelke, polnjene s tem agensom (Heller, 1984, str. 13). Manjše koncentracije tega strupa povzročijo slepoto, vnetje kože in mehurje, večje pa poškodbo pljuč in zadušitev. Iperit ima grozljivo lastnost, da ne prehaja $v$ telo samo skozi dihala kakor klor, pač pa poškoduje tudi kožo ter povzroči mehurje po vsem telesu, poškodbe vidnih sluznic, dihal ter kostnega mozga in limfatičnega sistema. Gre za tako agresiven agens, da prodira ne samo v človeško tkivo, pač pa celo v materiale, kot so usnje, les, guma ipd. Poleg tega je iperit obstojen tudi pri nizkih temperaturah, pri višjih temperaturah se obstojnost zmanjšuje, poveča pa se možnost nastanka hlapov. Za zaščito ni dovolj plinska maska, potrebna je tudi zaščita kože po celem telesu, za kar pa navadna obleka ni dovolj (Ivanuša, 2008, str. 148). Znaki kontaminacije se lahko pojavijo šele več ur pozneje, tako da žrtve sprva niti ne slutijo, kaj jih je doletelo (Brezina, 2005, str. 25).

Po poročilu Wilhelma Westphala je Haber opozoril generala Ludendorffa, naj Nemčija uporabi iperit le, če namerava $v$ enem letu zmagati $v$ vojni. V nasprotnem primeru bi se po opozorilu Haberja lahko zgodilo, da bi zavezniki izdelovali to smrtonosno orožje sami, zaradi česar Nemčija ne bi bila sposobna nadomestiti kontaminiranih uniform in industrijsko proizvesti zadosti oblačil za vojake. Že samo to dejstvo bi bilo lahko usodno za Nemčijo (Jones, 2014a).
} 
nemške uporabe strupenega orožja je bil aprila 1918 ob zavzetju mesta Armentières. Mesto so bombardirali z iperitom tako silovito, da so priče omenjale tekoči iperit, ki je tekel po ulicah. Britanci so evakuirali prebivalce mesta, ki je bilo tako kontaminirano, da Nemci še dva tedna niso mogli vstopiti (Heller, 1984, str. 27). Leta 1918 so iperit uporabljali tudi Britanci proti nemškim vojakom. Tako so ga med drugim uporabili 13. oktobra 1918 v bližini belgijske vasice Werwick. Med žrtvami je bil tudi pehotni desetnik Adolf Hitler, ki je utrpel začasno oslepitev in ožganine na koži (Hutchinson, 2004, str. 209).

Zaradi zastrašujočih posledic ostaja iperit nevarno bojno sredstvo še danes, čeprav je prepovedan z mednarodnimi konvencijami (Hutchinson, 2004, str. 210). Nekateri vojaški strokovnjaki menijo, da je gorčični plin najbolj nevaren od vseh kemičnih agensov. Iperit je namreč zelo obstojen in po uporabi nevaren za okolico še dolgo časa (Browne, 1995). ${ }^{8}$

\section{PREOSTALI KEMIČNI AGENSI PRVE SVETOVNE VOJNE}

V prvi svetovni vojni so na obeh straneh preizkusili več različnih bojnih strupov, vendar so $\mathrm{v}$ velikih količinah proizvajali in uporabljali samo nekatere izmed njih: klor $(\mathrm{Cl})$, fosgen (karbonilklorid $-\mathrm{CCI}_{2} \mathrm{O}$ ), difosgen (triklorometil kloroformat $-\mathrm{C}_{2} \mathrm{CI}_{4} \mathrm{O}_{2}$ ), klorpikrin (trikloronitrometan $-\mathrm{CI}_{3} \mathrm{CNO}_{2}$ ), hidrogen cianid (cianovodikova kislina - pruska kislina - HCN), cianogen klorid (CCIN) in iperit (bikloroetil sulfid $-\mathrm{C}_{4} \mathrm{H}_{8} \mathrm{CI}_{2} \mathrm{~S}$ ). Slednji so se izkazali za najbolj učinkovite in uporabne na bojiščih. Klorpikrin je prvič uporabila Rusija avgusta 1916, pozneje pa so ga uporabljale vse vojskujoče se sile. Cianovodikovo kislino so prvič na bojišču preizkusili Francozi 1. julija 1916 na Sommi, pozneje so jo uporabljali tudi Britanci in Francozi (Ochsenbein, 2007). Na seznamu agensov, ki so jih še sintetizirali in preizkusili na bojišču, najdemo: brom $(\mathrm{Br})$, hidrogen sulfid $\left(\mathrm{H}_{2} \mathrm{~S}\right)$, cianogen bromid (bromcianid - $\mathrm{BrCN})$, diklorometil eter $\left(\mathrm{C}_{2} \mathrm{H}_{4} \mathrm{Cl}_{2} \mathrm{O}\right)$, metil cianoformat $\left(\mathrm{C}_{3} \mathrm{H}_{3} \mathrm{NO}_{2}\right)$, etil cianoformat $\left(\mathrm{C}_{4} \mathrm{H}_{5} \mathrm{NO}_{2}\right)$, metansulfonil klorid $\left(\mathrm{CH}_{3} \mathrm{CIO}_{2} \mathrm{~S}\right)$, etansulfonilklorid $\left(\mathrm{C}_{2} \mathrm{H}_{5} \mathrm{ClO}_{2} \mathrm{~S}\right)$, etildikloroarzin $\left(\mathrm{C}_{2} \mathrm{H}_{5} \mathrm{AsCl}_{2}\right)$, metildikloroarzin $\left(\mathrm{CH}_{3} \mathrm{AsCl}_{2}\right)$, etildibromoarzin $\left(\mathrm{C}_{2} \mathrm{H}_{5} \mathrm{AsBr}_{2}\right)$, Clark I (difenilarzinklorid - $\mathrm{Cl}_{2} \mathrm{H}_{10} \mathrm{AsCI}$ ), Clark II (difenilarzincianid $-\mathrm{Cl}_{3} \mathrm{H}_{10} \mathrm{AsN}$ ), adamzit (difenilaminoklorarzin $-\mathrm{C}_{12} \mathrm{H}_{9} \mathrm{AsCIN}$ ), kloracetofenon $\left(\mathrm{C}_{8} \mathrm{H}_{7} \mathrm{ClO}\right.$ ) idr. (A short History of $\mathrm{CW}$ during WWI., online in Ochsenbein, 2007).

V začetku vojne Rusija ni bila sposobna proizvajati svojega kemičnega orožja in je bila odvisna od britanske pomoči. Pozneje je razvila tudi svojo industrijo klora, klorpikrina in fosgena, vendar je šlo za bistveno manjšo produkcijo kot v Nemčiji. Rusi so izvedli prve kemične napade pri Kunilovem septembra in oktobra 1916, vendar so imeli velike težave z lastno zaščito, saj niso imeli učinkovitih plinskih mask (A short History of CW during WWI., online).

\footnotetext{
Na območju zahodne fronte so francoski kmetje še 40 let po koncu prve svetovne vojne poročali, da so drevesni štori, kontaminirani z iperitom, še vedno tako nevarni, da sedenje na njih povzroča poškodbe na koži (Browne, 1995).
} 
Američani so se sicer aktivno vključili v vojno šele aprila 1917, dve leti po prvem uspešnem nemškem plinskem napadu na zahodni fronti. Čeprav so se zavedali povečane uporabe kemičnega orožja na evropskih bojiščih, so se začeli na kemično vojno pripravljati šele dva meseca, preden so vstopili v vojno na strani antantnih sil. Tako so prispele prve ameriške enote v Francijo brez znanja in opreme za kemično vojno. V tem pogledu so bili popolnoma odvisni od zaveznikov. Prizadevali so si čim hitreje nadomestiti primanjkljaj z urjenjem vojakov in razvojem protikemične zaščite, vendar v tem niso bili vedno uspešni. Na bojišču so se srečevali s krutim in neslišnim sovražnikom, ki se je širil vsepovsod - zalezel se je v uniforme, hrano, vodo, opremo, orožje in celo v blato v jarkih (Heller, 1984). Zaostajanje v razvoju kemičnega vojskovanja so Američani želeli prekiniti tudi z znanstvenimi raziskavami. Sintetizirali so novo kemično orožje, imenovano levizit (angl. lewisite) po kemiku, ki ga je prvi izdelal, stotniku Winfordu Lee Lewisu. ${ }^{9}$ Šele v zadnjih mesecih vojne so začeli masovno proizvajali to sredstvo in prva pošiljka je prispela na zahodno fronto, ko je bilo že sklenjeno premirje. Zaradi nenadnega premirja je nevarni tovor pristal v Atlantiku (Hutchinson, 2004, str. 210).

\section{PLINSKA VOJNA NA SOŠKI FRONTI}

Kemično orožje sta imeli tudi Avstro-Ogrska in Italija, tako da so bili kemični agensi uporabljeni tudi na slovenskih tleh, saj je bila glavnina ofenzivnega delovanja obeh sil osredotočena prav na soško bojišče. Prvi plinski napad je bil na soški fronti izveden 29. junija 1916 na Debeli Griži (Monte San Michele), ko so avstro-ogrski vojaki odprli jeklenke, napolnjene $\mathrm{z}$ mešanico klora in fosgena. Iz jeklenk so skozi svinčene cevi plin usmerili proti italijanskim položajem. Italijanska vojska ni imela plinskih mask in žrtve so bile velike. Avstrijci izkušenj z uporabo bojnih strupov pred tem niso imeli, pa tudi plinske maske so imele samo posebne enote, zaradi česar je umrlo tudi 40 avstro-ogrskih vojakov. Avstrijska vojska je uporabila to orožje v obupu, saj je italijanska artilerija silovito napadala njihove položaje. Italijani so bili na ta napad popolnoma nepripravljeni. Po njihovih ocenah so v napadu izgubili $6700 \mathrm{mož,} \mathrm{od}$ katerih je bilo 2700 mrtvih. Italijanskega topništva pa strupeni agens ni dosegel in to je odločno odgovorilo na avstrijski plinski napad. Avstrijsko vojaško vodstvo zato napada s plinom ni imelo za posebno uspešnega (Klavora, 2010, str. 133).

Italijanske enote so na soškem bojišču skladiščile bojne strupe, vendar ni zanesljivih poročil, da bi jih res uporabili v boju. Po vojni so na območju fronte odkrili večje število plinskih granat italijanskega izvora (Klavora, 1993). ${ }^{10}$

\footnotetext{
Levizit je sredstvo s podobnim učinkom kot iperit (Crone, 1992, str. 18). Gre za arzenov mehurjevec, ki je v tekoči obliki brez vonja, kadar pa vsebuje nekaj nečistoč, ima vonj po geraniji. Poškoduje kožo in sluznice, težja zastrupitev pa lahko povzroči slepoto (Ivanuša, 2008, str. 153).

${ }^{10}$ Septembra 1998 so v Soči pod mostom nad Avčami odkrili večje število neeksplodiranih italijanskih plinskih granat, napolnjenih s fosgenom. Akcija uničenja je imela zahtevne priprave in precejšen finančni vložek, saj je odlagališče plinskih granat pomenilo resno nevarnost za okolico. Posamezne granate so bile že korodirane, tako da bi bojni strup ob višji temperaturi lahko uhajal v okolje (Ǔ̌eničnik, 1999, str. 289).
} 
Avstro-ogrska vojska je ponovno uporabila fosgen na soški fronti v začetku znamenite dvanajste ofenzive v sodelovanju z zavezniki Nemci. Ofenziva je potekala v Zgornjem Posočju, med Bovcem in Tolminom, temeljila pa je na presenečenju, uporabi bojnega plina in bliskoviti skupni akciji pehote in topništva. Namen plinskega napada je bil doseči gorske hrbte, strma pobočja in ozke doline, v katerih so bile nevarne italijanske topniške kaverne in opazovalnice. Granate in mine z bojnim strupom so prispevali Nemci. Da bi onesposobili italijanske položaje, so centralne sile uporabile granate, polnjene $\mathrm{z}$ dvema kemičnima agensoma, in sicer s plinom difosgenom in agensom, imenovanim tudi clark (difenilarzinklorid). Kombinacija obeh plinov je bila namenska: clark so uporabili, ker je prehajal tudi skozi filter tedanjih plinskih mask. Povzročil je močno kašljanje, kihanje, bolečine v prsih in tudi bruhanje, zato je bila žrtev prisiljena sneti masko. Takoj, ko je vojak snel masko, je vdihnil še difosgen, kar je ob primerni koncentraciji povzročilo smrt. Difosgen so uporabili, ker je obstojen tudi pri nizkih temperaturah. Nemci so vedeli, da imajo Italijani slabe plinske maske ali pa jih sploh nimajo (Klavora, 2010, str. 134). Poleg plinskih min in granat so Nemci pripeljali v Bovško kotlino še plinomete. ${ }^{11}$ Hkratna izstrelitev večjega števila min je omogočila tolikšno koncentracijo plina, da celo plinske maske niso zadostovale. Poleg plinometov so uporabili tudi topove, ki so izstreljevali plinske granate (Klavora, 2010, str. 134). Centralnim silam je bilo v dvanajsti ofenzivi naklonjeno tudi vreme, saj se je megla kot pokrov spustila nad kotlino in še povečala učinek plinskega napada. Plinski napad je trajal dve uri in pol. Plinske enote in artilerija so imele navodila, da v tem času izstrelijo celotno količino granat, najprej tiste z modrim križem, nato pa še tiste z zelenim križem. V tem času se je prostor med Bovcem in Sočo spremenil v eno samo pokopališče. Plinska smrt je pokosila vojake, podgane in tovorne živali (Klavora, 1993). Prizadet je bil predvsem bataljon italijanske brigade Friuli in čeprav po mnenju Klavore plinski napad ni bil odločilen dejavnik, da se je italijanska obramba na Bovškem polju sesula, je oslabil moralo in bojno moč italijanskih vojakov s strahom in paniko, ki ju je povzročil (Klavora, 2010, str. 134).

\section{PSIHOLOŠKI UČINKI}

Zaradi zastrašujočih posledic uporabe kemičnega orožja je to postalo tako fizično kakor tudi psihološko orožje. V vojaških vrstah se je povečeval strah pred plinskim napadom, ki se je v posameznih primerih stopnjeval tudi do panike in živčnega zloma. Vojaki obeh strani so bili prepričani, da je kemično vojskovanje nečloveško, da krši pravila vojskovanja in s svojo krutostjo presega načela humanosti. Vojaki tudi niso bili prepričani, ali je njihova zaščitna maska zares učinkovita ali pa je morda filter že neuporaben. S stopnjevanjem uporabe kemičnega orožja je negotovost povzročala vse več psiholoških težav. Nemški izum iperita je negotovost in strah še povečeval (Fitzgerald, 2008). Psihološki učinek bojnih strupov je nastajal tudi zaradi nevidnega in neslišnega delovanja kemičnih agensov. Problematična je bila zaznava

\footnotetext{
${ }^{\prime \prime}$ Plinomet je bila cev, ki so jo pred uporabo zabili v zemljo in napolnili s plinsko mino, vžig mine pa je bil električni. Plinomete so prvič uporabili že Britanci 4. avgusta 1917 pri Arrasu v Franciji. Plinomet je bila cev, ki so jo pred uporabo zabili v zemljo in napolnili s plinsko mino, vžig mine pa je bil električni (Klavora, 2010).
} 
prisotnosti tega tihega ubijalca oziroma je prepozno odkritje povzročilo tisoče žrtev. Vsi ti dejavniki so ustvarjali vtis misterioznosti bojnih strupov in povečevali strah pred njimi (Burck in Flowerree, 1991, str. 14).

\section{0 ŽRTVE KEMIČNE VOJNE}

Jeklenke, granate in izstrelki, napolnjeni s kemičnim orožjem, so v prvi svetovni vojni pomenili okoli 25 odstotkov uporabljenega streliva na obeh straneh. Kljub izboljšavam plinskih mask in druge zaščitne opreme so strupeni plini zahtevali več kot milijon smrtnih žrtev, kar je slabih pet odstotkov vseh žrtev zaradi orožja. V precej primerih so žrtve sicer preživele napad s plinom, vendar so pozneje zaradi različnih poškodb umrle zaradi bolezni. Po navedbah Prentissa je v prvi svetovni vojni kemično orožje povzročilo 1.296 .000 žrtev, od katerih je bilo 91.000 smrtnih. Te ocene najbrž niso zanesljive, saj je resnično število žrtev verjetno večje. Upoštevati moramo, da so se pri veliko veteranih posledice kemične vojne pokazale šele po vojni, in vprašanje je, koliko teh žrtev je vključenih v uradne številke (A short History of CW during WWI., online).

Med vsemi vojskujočimi se silami so Rusi utrpeli najhujše izgube zaradi kemičnega orožja, in sicer 56.000 mrtvih od skupaj 420.000 žrtev (okoli 11 odstotkov), predvsem zaradi slabe opremljenosti z zaščitnimi maskami. Tabela spodaj prikazuje število žrtev uporabe kemičnih agensov v prvi svetovni vojni po državah. Prikazuje razliko med številom vseh prizadetih in številom smrtnih žrtev, pri čemer je treba upoštevati, da je približno 12 odstotkov vseh prizadetih in preživelih vojakov čutilo posledice kemičnega napada vse življenje, torej tudi po končani vojni (Hutchinson, 2004, str. 210-211).

\begin{tabular}{rl|l|c|}
\multirow{2}{*}{$\begin{array}{c}\text { Tabela: } \\
\text { Žrtve kemičnih } \\
\text { agensov v prvi } \\
\text { svetovni vojni }\end{array}$} & Država & Vse žrtve (smrtne in preživeli) & Smrtne žrtve \\
\cline { 2 - 4 } & Rusija & 420.000 & 56.000 \\
\cline { 2 - 4 } & Nemčija & 191.000 & 9000 \\
\cline { 2 - 4 } & Francija & 182.000 & 8000 \\
\cline { 2 - 4 } & Velika Britanija (vključno s Kanado) & 180.597 & 8109 \\
\cline { 2 - 4 } & Avstro-Ogrska & 100.000 & 3000 \\
\hline & ZDA & 69.975 & 1462 \\
\cline { 2 - 4 } & Italija & 60.000 & 4627 \\
\cline { 2 - 4 } & Skupaj & 1.203 .572 & 90.198 \\
\hline
\end{tabular}




\section{KEMIČNI AGENSI PO PRVI SVETOVNI VOJNI}

Uporaba kemičnega orožja v prvi svetovni vojni je sicer povzročila ogorčenje mednarodne javnosti, vendar je bilo kljub temu med obema vojnama nekaj primerov uporabe kemičnega orožja. Britanci so uporabili kemični agens adamzit v boju proti boljševikom v ruski državljanski vojni leta 1919. Boljševiki so uporabili strupeni plin pri zatiranju upora pod vodstvom Aleksandra Antonova pri Tambovu leta 1920. Tudi španske oblasti so istega leta s kemičnim orožjem zatrle upor v Maroku. Iperit so uporabili Italijani v italijansko-abesinski vojni (danes Etiopija) leta $1935 \mathrm{v}$ razpršeni obliki iz letal, zaradi česar je umrlo ali bilo poškodovanih približno 150.000 ljudi. Prav tako so kemično orožje uporabili Japonci v Mandžuriji proti kitajskemu civilnemu prebivalstvu in vojaškim silam v letih od 1937 do 1945 (Hutchinson, 2004, str. 212-214).

Napredovala je tudi kemijska znanost. Nemški znanstveniki, ki so se ukvarjali z insekticidi, so sintetizirali prve živčne strupe: leta 1936 tabun, leta 1938 sarin in leta 1944 soman. ${ }^{12} \mathrm{Na}$ srečo Nemčija v drugi svetovni vojni tabuna in sarina iz različnih vzrokov ni uporabila na bojišču. Zaloge bojnih strupov, ki so jih imele države med drugo svetovno vojno, so bile ogromne: ZDA so proizvedle 135.000 ton kemičnega orožja, Nemčija 70.000 ton, Velika Britanija 70.000 ton in Japonska 7500 ton. Vse zaloge kemičnega orožja, ki so bile izdelane med drugo svetovno vojno, se ocenjujejo na več kot 600.000 ton (Hutchinson, 2004, str. 216). Nemčija po količini sicer ni prednjačila, vendar je imela kemične agense s precej večjo učinkovitostjo od drugih držav in je napačno predvidevala, da so sovražne države z raziskavami enako napredovale kot nemška kemijska znanost. Razlogi, da večje uporabe kemičnega orožja v drugi svetovni vojni kljub obilnim zalogam ni bilo, so različni. Po eni strani je bila uporaba kemičnega orožja prepovedana, po drugi strani pa so se vpletene strani bale nasprotnikovih povračilnih ukrepov. ${ }^{13}$ Nemčija se je v drugi svetovni vojni bala povračilnih ukrepov zaveznikov, ki so imeli premoč v zraku in bi jo lahko izkoristili za napad na nemško prebivalstvo. Nemške sile so napačno predvidevale, da imajo zavezniki kemično orožje enake uničevalne sile kot Nemci in so se tudi zato bale povračilnih ukrepov (Cobb, 2000, str. 48).

Po vojni so se države spraševale, kako kemično orožje uničiti. Vse do 60. let prejšnjega stoletja je bilo veliko naloženega na zastarelih ladjah in potopljenega sredi oceanov in morij. Od novembra 1945 do aprila 1946 so tudi v Jadranskem morju Američani potopili veliko fosgena, iperita, hidrogen cianida, levizita in cianogen klorida (Baker, 2006, str. 13). Američani so zastarelo kemično orožje potapljali v oceane še leta 1970. S potopitvijo postanejo živčni strupi neučinkoviti in se raztopijo v vodi, toda iperit je netopljiv, oksidira in tvori debelo plast okoli osrednjega dela mase, ki ostane nevarna tudi pod vodo. Ribiči so pogosto poročali o zastrupitvah rib

12 Živčni agensi trajno blokirajo prenos živčnih dražljajev po telesu in povzročajo izgubo nadzora mišic, odpoved dihalnih organov in smrt. Problematični so še posebej, ker učinki niso takojšnji, nimajo vonja in jih je težko izslediti (Cobb, 2000, str. 47).

${ }^{13}$ Nekateri menijo, da Hitler (razen ciklona B proti Judom v koncentracijskih taboriščih) kemičnega orožja ni uporabljal, ker je bil kot vojak v prvi svetovni vojni sam žrtev zastrupitve s plinom (Broyles, 2005). 
z iperitom. Okoljevarstveniki menijo, da so potopljene ladje, nakopičene s kemičnim orožjem, ekološka časovna bomba, ki tiktaka na tleh svetovnih morij in oceanov. Ocene so, da je na morskih tleh odvrženih okoli 500.000 ton kemičnega orožja. Podvodne raziskave so sicer potrdile le majhen vpliv na lokalni ekosistem, vendar se nevarnost z leti ne zmanjšuje (Hutchingson, 2004, str. 225).

Medtem ko je bila uporaba kemičnega orožja po prvi svetovni vojni razmeroma omejena, pa so raziskave na tem področju napredovale tudi po drugi svetovni vojni. Čeprav so nekateri menili, da bo v atomski dobi po iznajdbi in uporabi jedrskega orožja postalo kemično orožje odveč, so kemiki menili drugače (Kessler, 1948). Leta 1953 so odkrili živčni bojni strup, imenovan VX, ${ }^{14} \mathrm{~V}$ 80. pa binarno kemično orožje, ki omogoča lažje uničenje, hkrati pa se strupenost kemikalije s časom skladiščenja ne zmanjšuje (Cobb, 2000, str. 48). ${ }^{15}$

Tudi v spopadih po drugi svetovni vojni so bile odločitve za uporabo kemičnega orožja precej redke (na primer Irak, ki je uporabil kemično orožje v vojni proti Iranu (Jogan, 1993)). Prav tako je leta 1988 Saddam Hussein uporabil kemično orožje (najverjetneje iperit, VX in sarin) v napadu na Kurde v Severnem Iraku (Broyles, 2005). V času hladne vojne so Sovjetska zveza in ZDA imele več kot 100.000 ton kemičnega orožja, kar naj bi zadostovalo za uničenje celotne človeške populacije na zemlji (Jerič, 2013). Za bojne namene naj bi bili v tem obdobju najbolj uporabni iperit in živčni strupi (Crone, 1992). V vietnamski vojni so ZDA v boju proti silam Viet Conga uporabile herbicide oziroma defoliante v obilnih količinah (več deset milijonov litrov). Pri tem je bil posebej uničevalen herbicid s kodnim imenom Agent Orange, ki so ga prašili po gozdovih in poljih. Namen je bil uničiti gozdove, ki so dajali zavetje vietnamskim vojaškim silam. Tako je bilo uničeno rastlinje na okoli 13 odstotkih površine Južnega Vietnama. Čeprav so ZDA trdile, da so uporabile kemikalije samo v obrambne namene, so z njimi povzročile resne zdravstvene težave in številne zastrupitve ter telesne poškodbe, zaradi katerih je trpelo več sto tisoč ljudi. Uporabile so namreč pesticid, ki vsebuje dioksin, ta pa povzroča raka, razvojne nepravilnosti pri novorojenčkih in druge trajne zdravstvene težave (Brezina, 2005, str. 26). Izkazalo se je, da je imela raba tega pesticida posledice tudi za zdravje ameriških vojakov, njihovih potomcev in ne le vietnamskih prebivalcev (Broyles, 2005). ${ }^{16}$

\footnotetext{
${ }^{14}$ VXje po učinkih podoben tabunu in sarinu, vendar precej bolj nevaren zaradi večje obstojnosti. Kot plin lahko ostane aktiven še tri do štiri tedne po uporabi, smrten pa je že v majhnih koncentracijah (Cobb, 2000, str. 48).

${ }^{15}$ Gre za dve prekurzorski spojini, ki se tik pred uporabo zmešata, pri čemer nastane strupena oblika spojine (Cobb, 2000, str. 48).

${ }^{16}$ Kemično orožje je izdelovala tudi socialistična Jugoslavija v skrivnih obratih Jugoslovanske ljudske armade, v največjih količinah v 80. letih prejšnjega stoletja. Najbolj znani so obrat v vasi Potoci v bližini Mostarja, obrat $v$ Lučanih v Srbiji in tovarna Prva iskra v Bariću v Srbiji (Tihi, 2001). Prednost so dajali predvsem sarinu, ki so ga izdelovali $v$ večjih količinah, druge bojne strupe pa so sintetizirali predvsem eksperimentalno. Sarin je JLA prodajala arabskim državam, med drugim tudi Iraku za boj proti Kurdom (Jurilj, 2013).
} 


\section{UPORABA KEMIČNEGA OROŽJA V TERORISTIČNE NAMENE}

Kemično orožje za svojo izdelavo ne zahteva izjemno visoke tehnologije, pa tudi posebno visokih finančnih sredstev ne, zato je privlačno za uporabo v teroristične namene. Po Barnabyju je kemično orožje najbolj dosegljivo teroristom. Za izdelavo zadostuje znanje kemije in dostop do laboratorija - nekateri bojni strupi pa se lahko izdelajo celo v kuhinji ali kleti. Poleg tega je mogoče proizvodnjo bojnih strupov prikriti v civilni kemični ali farmacevtski industriji. Zato velja kemično orožje za jedrsko bombo siromakov (v Šket Jarm, 2006, str. 45). Kemikalije, iz katerih se lahko kemično orožje izdela, uporablja kemična industrija za najbolj vsakodnevne namene (npr. za izdelavo zobne paste, pesticidov, kozmetike, v tiskarnah, medicini itn.) (Ciraj, 1999). Znanih je več kot 50.000 različnih kemikalij, ki bi se jih lahko uporabilo kot kemično orožje (na primer klor). Izdelava bomb je precej preprosta in v knjižnicah je dostopna literatura s shematičnimi opisi tega orožja iz časa prve svetovne vojne (Reddy, 2007). Kemični agensi se lahko uporabijo v zaprtih prostorih ali se z njimi kontaminirata hrana in voda (Cobb, 2000, str. 33). Kemično orožje tako predstavlja »orožje prihodnosti« in ima potencial destabilizacije varnostnega sistema ter njegovega zloma (Podbregar in Ivanuša, 2013).

V 20. stoletju je bilo kemično orožje uporabljeno leta 1946, ko je skupina Maščevanje izraelske krvi (hebrejsko Dahm Y'Israel Nokeam) želela z arzenikom zastrupiti pripadnike SS v vojaškem kompleksu zaporov blizu Nürnberga, da bi maščevala žrtve holokavsta (Tucker, 2000, 250). Kemično orožje je v terorističnih akcijah večkrat uporabila tudi japonska verska sekta Aum Shinrikyo. Najbolj odmevna je bila njena akcija leta 1995 na podzemni železnici v Tokiu, ko je bilo zaradi uporabe živčnega bojnega strupa sarina poškodovanih 5510 ljudi, umrlo pa jih je 12 (Seto, 2001). Pripadniki sekte so sarin izdelovali sami ${ }^{17}$, zato njegova koncentracija ni bila največja in je bilo število smrtnih žrtev razmeroma nizko, ob boljši kakovosti pa bi povzročil tisoče mrtvih (Cobb, 2000, str. 55).

Primer Aum Shinrikyo odkriva tudi negativne strani uporabe kemičnega orožja. Problematično je namreč razprševanje strupenega sredstva, pa tudi skladiščenje $\mathrm{v}$ ohišju, ki preprečuje izhlapevanje. To so dejavniki, ki otežujejo morebitno izdelavo kemičnega orožja manjšim skupinam brez posebnega znanja in materialov. Teroristi lahko razširijo kemično orožje po prostoru s pomočjo ventilatorjev (Matsumoto, 1994), vrečk s strupi (Tokio, 1995), bomb s strupi (npr. v avtomobilih), razpršilcev, ki so nameščeni na letalih (npr. za škropljenje njiv) itn. Kemično orožje lahko tudi primešajo hrani in vodi (Burck in Flowerree, 1991, str. 585).

Kemično orožje pa ni bilo uporabljeno samo za teroristične namene, temveč tudi za nekatere protiteroristične akcije. Najbolj odmevna je bila akcija ruskih specialnih sil v moskovskem gledališču Dubrovka oktobra 2002, ko je bilo v boju proti čečenskim teroristom uporabljeno kemično orožje neznane sestave. Čečenski teroristi so

\footnotetext{
${ }^{17}$ Sarin namreč odlikujeta enostavna izdelava in dostopnost sestavin. Recept za izdelavo sarina je bil podoben tistemu, ki ga je uporabljala sovjetska armada in najverjetneje so ga pripadniki kupili od visokega predstavnika ruskih oblasti (Kaplan, 2000, 213-216).
} 
ugrabili kar 850 gledalcev in igralcev ter jih imeli v gledališču kot talce. Po uporabi skrivnostnega kemičnega orožja je bilo vseh 40 do 50 čečenskih teroristov mrtvih in poleg njih še 129 talcev. Čečenski teroristi so bili sicer žrtve strelnega orožja specialnih sil, toda talci so podlegli neznanemu kemičnemu plinu, ki je poškodoval tudi nekaj pripadnikov specialnih sil (Krechetnikov, 2012).

\section{PRAVNE PREPOVEDI UPORABE KEMIČNEGA OROŽJA}

Ob koncu 19. stoletja so se evropske sile že zavedale morebitne nevarnosti novega orožja in so hotele omejiti njegov razvoj in uporabo. Primer je sprejetje Haaške konvencije leta 1899 in Haaške konvencije o kopenskem vojskovanju leta 1907, ki sta prepovedali uporabo projektilov, polnjenih s strupi, in strupenih plinov v bojne namene (Höfer, 2002). Ne glede na sprejetje obeh konvencij pa je bilo do konca prve svetovne vojne proizvedenih več kot 124.000 ton bojnih strupov. Izrazoslovje obeh konvencij je bilo slabo izbrano in zato so določila dopuščala različne interpretacije, ${ }^{18}$ konvencij pa niso upoštevale niti centralne niti antantne sile (Fitzgerald, 2008).

Po Veliki vojni je mednarodna skupnost želela urediti področje pravnih omejitev uporabe kemičnega orožja. Z mirovno pogodbo v Versaillesu leta 1919 je bila tako Nemčiji prepovedana proizvodnja kemičnega orožja (Broyles, 2005). Leta 1925 je bil v Ženevi podpisan Protokol o prepovedi vojaške uporabe plinov in bakterioloških metod vojskovanja. Ta protokol, znan kot Ženevski protokol, je prepovedal uporabo kemičnega orožja v vojni, ni pa prepovedal skladiščenja, proizvodnje in razvoja kemičnega orožja (Ciraj, 1999, str. 285). Protokola nista podpisali Japonska in ZDA. Ženevski protokol so ZDA ratificirale šele leta 1975, potem, ko so uporabile pesticide v vietnamski vojni v vojaške namene (Brezina, 2005, str. 25-27).

Odločitev za pripravo bolj obvezujočega dokumenta o prepovedi kemičnega orožja je bila sprejeta na konferenci o razoroževanju leta 1980. Pogajanja so se zavlekla vse do 90. let, zaradi česar je bil Ženevski protokol edina mednarodna pravna omejitev uporabe kemičnega orožja vse do leta 1993 (Brezina, 2005, str. 27). Konvencijo o kemičnem orožju (Chemical Weapons Convention) je 13. januarja 1993 slovesno podpisalo 150 držav, med njimi tudi Slovenija. V svetovnem merilu je začela veljati 29. aprila 1997. Konvencija določa prepoved razvoja, proizvodnje kemičnega orožja in obvezno uničenje njegovih zalog. Dovoljuje rabo nekaterih kemičnih agensov, na primer solzivca, v policijske namene, vendar zahteva, da imajo sredstva, uporabljena $\mathrm{v}$ te namene, le kratkotrajne učinke, ki ne puščajo resnih zdravstvenih posledic. Leta 1997, ko je začela konvencija veljati, sta ZDA in Rusija posedovali okrog 95 odstotkov svetovnih zalog kemičnega orožja. ZDA načrtujejo, da bodo uničile vse zaloge kemičnih agensov do leta 2021, Rusija pa do leta 2015 (Jane's, str. 11 in 12). Za uresničevanje določb konvencije na svetovni ravni je bila ustanovljena Organizacija za prepoved kemičnega orožja (Organisation for the Prohibition of Chemical Weapons; v nadaljevanju OPCW) (Ciraj,1999, str. 285). OPCW ima sedež v Haagu

18 Tako so Nemci trdili, da so pri Ypresu uporabili jeklenke, iz katerih se je širil klor, česar po njihovem mnenju konvenciji nista prepovedovali, saj sta omenjali le projektile z bojnimi strupi (Hutchinson, 2004, str. 199). 
na Nizozemskem, njena naloga pa je preverjati, kako države spoštujejo Konvencijo o kemičnem orožju, lahko pa v posamezno državo pošlje tudi inšpektorje (Jerič, 2013). Vsaka država podpisnica omenjene konvencije je tudi članica OPCW, kar pomeni, da so zunaj organizacije le še štiri države, in sicer Angola, Egipt, Severna Koreja in Južni Sudan.

\section{KEMIČNA NEVARNOST DANES}

Danes poskuša mednarodna skupnost z delovanjem Organizacije za prepoved kemičnega orožja zmanjšati nevarnost nastanka zaradi kemičnih agensov škodljivih posledic za človeštvo. Ne glede na pravne prepovedi pa zveza Nato pojmuje nevarnost kemičnih sredstev in JRKB-orožij kot še vedno prisotno in celo bolj nevarno od klasičnega orožja. Toksične industrijske nevarnosti so samo del tega. Skladno s tem zahteva Nato od svojih članic tudi, da poskrbijo za ukrepe JRKB-obrambe (AJP-3(B), str. 1-16). Koncept upravljanja naravnih in industrijskih nevarnosti (angl. Concept for the Management of Environmental Industrial Hazards) vključuje širok spekter tveganj na območju delovanja oboroženih sil. Nevarnosti se nanašajo na nameren ali nenameren izpust toksičnih kemičnih agensov v okolje. Pristop k upravljanju vseh vidikov JRKB-nevarnosti opredeljuje tudi Natova doktrina AJP 3.8 Allied Joint Doctrine for NBC Defence. Doktrina zahteva od članic, ki prispevajo svoje enote v operacije zavezništva, sposobnost identifikacije, opozarjanja in poročanja v enotah ranga čete, ob toksičnih industrijskih incidentih pa zagotoviti primerno individualno in kolektivno zaščito. Tako ostaja naloga vsake posamezne države, da poskrbi za sredstva za protikemično zaščito, detekcijo in dekontaminacijo ter ohranja znanje o njihovi uporabi (Ivanuša, 2008, str. 156).

Sklep Izkušnja o uporabi kemičnega orožja v prvi svetovni vojni in o njegovih uničevalnih lastnostih je pomembna tudi za današnji čas. Po eni strani nam kaže učinek posameznih bojnih strupov na ljudeh, po drugi strani pa pripomore k razvoju zaščitnih sredstev in potrebnih medicinskih ukrepov za pomoč prizadeti civilni in vojaški populaciji. Ne glede na prepoved proizvodnje, kopičenja in uporabe kemičnega orožja pa njegova razmeroma poceni in preprosta izdelava pomeni stalno grožnjo za zdravje in življenje tako civilnega prebivalstva kakor tudi vojaških oseb. Posledice rabe nekaterih bojnih strupov so danes popolnoma enake kot tiste iz obdobja od 1914 do 1918, kar potrjuje, da so izkušnje iz prve svetovne vojne neprecenljive in še vedno uporabne.

Obdobje prve svetovne vojne je pomenilo preizkušanje različnih vrst kemičnega orožja in pokazalo njegove učinke in uspešnost rabe v boju. Izkazalo se je, da ima kemično orožje sicer lahko močnejše učinke na nasprotnikove enote, vendar je precej odvisno od vremenskih razmer, saj ob spremembi vremena lahko povzroči žrtve v lastnih vrstah, kar pomeni, da ni popolnoma zanesljivo. Izjemen razmah uporabe kemičnega orožja v prvi svetovni vojni ni vplival na končni izid vojne, saj se bojni strupi na bojišču niso vedno izkazali kot najbolj učinkoviti in še manj zanesljivi. Pokazalo se je, da so kemikalije, ki so ostale v vodi in zemlji, prav tako 
nevarne za napadalce kakor za sile v obrambi. To so tudi najpomembnejši vzroki, da se kemično orožje po letu 1918 ni več uporabljalo v takem obsegu, kot je značilno za prvo svetovno vojno. Čeprav si je mednarodna skupnost prizadevala z deklaracijami čim bolj omejiti proizvodnjo in uporabo kemikalij v bojne namene, pa sta glavna dejavnika, ki sta odvračala od njegove uporabe, nepredvidljivost in nevarnost tega orožja tudi za tistega, ki je bojne strupe uporabil. Prva svetovna vojna je že pokazala, da ima kemično orožje močan psihološki učinek in deluje zastraševalno ter povzroča zmedo in negotovost. Kemično orožje se je pozneje izkazalo za manj uporabno v vojaške namene, po drugi strani pa ima lastnosti, ki ga delajo učinkovitega za teroristične akcije. Izdelava kemikalij je precej poceni, njena uporaba pa povzroči paniko, močan odziv javnosti in posledice lahko ostanejo na prizadetem območju še daljši čas. Podzemni objekti, v katerih se zadržuje veliko ljudi, so še posebej privlačna tarča za kemični terorizem, saj se v njih kemične snovi zadržujejo dalj časa in lahko povzročijo več žrtev. Tako pomenijo kemični agensi danes nevarnost predvsem za uporabo $\mathrm{v}$ teroristične namene in manj kot bojno sredstvo, predvsem zaradi prizadevanja mednarodne skupnosti po globalnem izničenju teh nevarnih snovi.

1. A short History of Chemical Warfare during World War I. The Wayback Machine. https:// web.archive.org/web/19991023051711/http://www.mitretek.org/mission/envene/chemical/ history/ww1.html, 25. 8. 2014.

2. AJP-3(B), 2011. Allied joint doctrine for the conduct of operations. str. 1-16, http://www. cicde.defense.gouv.fr/IMG/pdf/20110316_np_otan_ajp-3b.pdf, 12. 8. 2014.

3. Baker, D., 2006. Biological, Nuclear \& Chemical Weapons. Florida: Rourke Publishing by Discovery Books.

4. Brezina, C., 2005. Weapons of Mass Destruction. Proliferation and Control. New York: The Rosen Publishing Group.

5. Browne, W. M., 1995. Terror in Tokyo: the Poison; Sarin Just One of Many Deadly Gases Terrorists Could Use. The New York Times. http://www.nytimes.com/1995/03/22/world/ terror-tokyo-poison-sarin-just-one-many-deadly-gases-terrorists-could-use.html, 17. 7. 2014.

6. Broyles, J., 2005. Chemical and Biological Weapons in a Post-9/11 World. New York: The Rosen Publishing Group.

7. Burck, M. G. and Flowerree, C. C., 1991. Chemical Weapons Proliferation. New York: Greenwood Press.

8. Ciraj, M., 1999. Konvencija o kemičnem orožju in njeno uresničevanje v Republiki Sloveniji. Ujma - revija za vprašanja varstva pred naravnimi in drugimi nesrečami. Str. 284-288.

9. Cobb, B. A., 2000. Biological and Chemical Weapons. The Debate Over Modern Warfare. New York: The Rosen Publishing Group.

10. Crone, D. H., 1992. Banning chemical weapons. The scientific background. Cambridge: University press.

11. Duffy, M., 2009. Weapons of War-Poison Gas. http://www.firstworldwar.com/weaponry/ gas.htm, 6. 8. 2014.

12. Fitzgerald, J. Gerard, 2008. Chemical Warfare and Medical Response During World War I. Am J Public Health. http://www.ncbi.nlm.nih.gov/pmc/articles/PMC2376985, 6. 8. 2014. 
13. Heller, E. C., 1984. Chemical Warfare in World War I: The American Experience, 19171918. V: Leaveanworth Papers, št. 10. Fort Leavenworth: Combat Studies Institute. http:// webharvest.gov/peth04/20041017045619/http://www.cgsc.army.mil/carl/resources/csi/ Heller/HELLER.asp, 28. 8. 2014.

14. Höfer, M., 2002. Chemische Kampfstoffe. V: Chemie in unserer Zeit. Št. 3, str. 148-155. http://www.cci.ethz.ch/vorlesung/de/Chemiegeschichte/Chemiewaffen.pdf, 28. 8. 2014.

15. Hofmann, S. J., 2014. Der erste Einsatz von Giftgas als Kriegswaffe. http://www.dw.del der-erste-einsatz-von-giftgas-als-kriegswaffela-17053767, 15. 7. 2014.

16. Hutchinson, R., 2004. Weapons of Mass Destruction. London: Cassell Military Paperbacks.

17. Ivanuša, T., 2008. Kemično orožje. V: Terorizem in jedrska, radiološka, kemična ter biološka obramba. Ljubljana: PDRIU, str. 137-172.

18. Jane's Nuclear, Biological and Chemical Defence 2011-2012, Surrey: IHS Jane's, IHS Global Limited, Sentinel House, Alexandria: Jane's Information Group Inc.

19. Jerič, P. A., 2013. Kemično orožje-jedrska bomba revnejših držav, http://www.rtvslo.si/ svet/kemicno-orozje-jedrska-bomba-revnejsih-drzav/317585, 20. 8. 2014.

20. Jogan, S., 1993. Začetek konca orožja za množično uničevanje. Teorija in praksa. 9-10, str. 999-1003.

21. Jones, S., 2014a. Yellow Cross: the advent of Mustard Gas in 1917. http:// simonjoneshistorian.wordpress.com/2014/02/04/yellow-cross-the-advent-of-mustard-gasin-1917/, 18. 8. 2014.

22. Jurilj, Z., 2013. Kako je otrov sarin iz Mostara završio u Iraku. Što je ostalo od tvornice bojnih otrova bivše JNA u Potocima kod Mostara. Večernji list. http://www.vecernji.ba/ kako-je-otrov-sarin-iz-mostara-zavrsio-u-iraku-613914, 25. 8. 2014.

23. Kaplan, E. D., 2000. Aum Shinrikyo. V: Toxic terror : assessing terrorist use of chemical and biological weapons. Cambridge: MIT Press, str. 207-226.

24. Kessler, F., 1948. Der chemische Krieg. V: Protar, št. 1-2, ETH-Bibliothek, Zürich, http://retro.seals.ch/cntmng?pid=zbk-001:1948:14::171, 15. 7. 2014.

25. Klavora, V., 1993. Plavi križ: Soška fronta: Bovec 1915-1917. Koper: Lipa.

26. Klavora, V., 2010. Uporaba bojnih plinov na soškem bojišču v letih 1916-1917. V: Soška fronta 1915-1917. Kultura spominjanja. Dunaj: Slovenski znanstveni inštitut; Ljubljana: Založba ZRC.

27. Krechetnikov, A., 2012. Moscow theatre siege: Questions remain unanswered. BBC News Europe. http://www.bbc.com/news/world-europe-20067384, 23. 7. 2014.

28. Legg, J., Parker, G., 2002. The Germans develop a new weapon: the gas cloud. The Great War. http://www.greatwar.co.uk/battles/second-ypres-1915/prelude/gas-development.htm, 30. 7. 2014.

29. Lejaille, A., 2013. Introduction: Prelude a la Grande Guerre Chimique. http://www. guerredesgaz.fr/these/Introduction/introduction.htm, 1. 9. 2014.

30. Lejaille, A., 2013. Vagues allemandes. http://www.guerredesgaz.fr/Agression/Lesvagues/ Allemandes/Allemandes.htm, 1. 9. 2014.

31. Ochsenbein, A., 2007. Dossier Chemische Kampfstoffe. Kampfstoff Ersteinsätze während dem 1. Weltkrieg. http://www.dtig.org/docs/BCW_3.pdf, 1. 9. 2014.

32. Podbregar, I. in Ivanuša, T., 2013. Proliferacija orožja za množično uničevanje - JRKB/E: novodobni izziv varnostnim silam v boju proti terorizmu. Sodobni vojaški izzivi. 4, str. 121-128.

33. Seto, Y., 2001. The Sarin Gas Attack in Japan and the Related Forensic Investigation. http://www.opcw.org/news/article/the-sarin-gas-attack-in-japan-and-the-related-forensicinvestigation/, 28. 7. 2014.

34. Šket Jarm, V., 2006. Orožje za množično uničevanje v Iranu, Iraku in Severni Koreji. Magistrsko delo. Ljubljana: Fakulteta za družbene vede. 
35. Reddy, C., 2007. The Growing Menace of Chemical War. http://www.whoi.edu/page. do? pid $=7342 \&$ tid $=282 \&$ cid $=25749$.

36. Tihi, Z., 2001. Kemijsko oružje iz Mostara. http://www.aimpress.ch/dyn/pubs/archive/ data/200111/11120-001-pubs-sar.htm, 18. 8. 2014.

37. Tucker, B. J., 2000. Lessons from the Case Studies. v: Toxic terror : assessing terrorist use of chemical and biological weapons. Cambridge: MIT Press, str. 249-269.

38. Ušeničnik, B., 1999. Odstranjevanje plinskih granat iz reke Soče. Ujma-revija za vprašanja varstva pred naravnimi in drugimi nesrečami, str. 289-294.

39. Wietzker, W., 2006. Giftgas im Ersten Weltkrieg. Was konnte die deutsche Öffentlichkeit wissen? Inaugural-Dissertation. Düsseldorf: Die Philosophische Fakultät der HeinrichHeine-Universität Düsseldorf.

40. Wottke, D., 2014. Kampfgas. http://www.alstergymnasium-hu.de/content/ProjektGeschichte/sites/mtg_kampfgas.html\#blaukreuz, 25. 8. 2014. 